\title{
Attaining Communicative Competency in Pharmacy \\ Practice: A Retrospective Analysis of the \\ Construction of a Communication Course for \\ International Pharmacy Graduates
}

\author{
Tim Mickleborough BSP RPh M.Ed. (corresponding author) \\ International Pharmacy Graduate Program \\ Leslie Dan Faculty of Pharmacy, University of Toronto, Toronto, ON M5S 3M2, Canada \\ Tel: 1-416-554-3504 E-mail: tim.mickleborough@utoronto.ca \\ Colette Peters $\mathrm{PhD}$ \\ International Pharmacy Graduate Program \\ Leslie Dan Faculty of Pharmacy, University of Toront, Toronto, ON M5S 3M2, Canada \\ E-mail: peterscolette@gmail.com
}

Received: April 6, 2015 Accepted: April 16, 2015 Published: May 4, 2015

doi:10.5296/jet.v2i2.7540 URL: http://dx.doi.org/10.5296/jet.v2i2.7540

\begin{abstract}
The ability to communicate effectively is an essential skill required by licensed pharmacists and it plays an integral role in meeting standards of practice. Acquiring the communication skills needed to successfully complete these standards of practice can be particularly challenging for International Pharmacy Graduates, or IPGs, many of whom are second language learners. This paper retrospectively analyses the construction of a communication course for IPGs, viewed through the theories of Lev Vygotsky and Donald Schön, which assists the IPGs in developing their communication skills for the Canadian context and applying them in increasingly independent ways. Course satisfaction surveys from two IPG cohorts were reviewed for qualitative feedback that would discuss the students' appreciation for the course design in relation to their learning. In general, students appreciated the learning supports in the first half of the course, but had more difficulty with the second half of the course that was designed to create a level of ambiguity that mimicked real life pharmacy practice. The authors felt more research is needed in this area of instruction design; however, this unique course design could have future implications for teaching communicative competency for international health care professionals.
\end{abstract}

Key words: Vygotsky, Schön, international pharmacy graduate, pharmacy communication, enculturation, bridging program, professional communication, communicative competency 


\section{Introduction}

The ability to communicate effectively is an essential skill required by licensed pharmacists and it plays an integral role in professional decision making. Austin and Galli (2003) consider communicative competency to be the primary skill pharmacists require in order to make clinical decisions, as, unlike many other health professionals, they do not perform physical assessments and most pharmacists are not trained to order and interpret lab tests. The importance of communicative competency in pharmacy practice is reflected in the National Association of Pharmacy Regulatory Authorities' (NAPRA) Standards of Practice for Canadian Pharmacists. According to NAPRA (2009), the Model Standard of Practice (MSOP) for the General Standard "Pharmacists communicate effectively," is described as follows:

Pharmacists, regardless of the role they are fulfilling:

- $\quad$ are proficient in written and verbal English or French

- use effective verbal, non-verbal, listening and written communication skills

- demonstrate sensitivity, respect, and empathy when communicating with diverse groups (p. 15)

Austin and Galli (2003) define communicative competency for pharmacists as consisting of more than simply linguistic fluency in reading, writing, listening and speaking. It necessarily incorporates other skills, such as cultural competency which encompasses aspects of communication that are interpersonal and culture-specific. Especially for the many international pharmacy graduates (IPGs) who are also second language learners, becoming a competent communicator in English in a professional context can be challenging as they may be unaware of the subtle nuances of pharmacy-specific communication. For the purposes of this paper, an IPG is defined as a pharmacist whose pharmacy-related training and degree comes from a university not within Canada or the United States. The focus of this article is the construction and evaluation of a course in the International Pharmacy Graduate Program (IPG program) at the University of Toronto called Patient Care Skills (P.C. Skills) that teaches IPGs communicative competency within the specific context of the patient/pharmacist interview.

\section{Background}

\subsection{Rationale for the IPG program}

In Ontario, Canada, one approach to supporting internationally educated professionals in attaining the communicative skills to meet the standards of their profession is "bridging education" programs, which are generally occupation specific. The International Pharmacy Graduate Program at the University of Toronto provides bridging education to help IPGs reach the professional standards described by NAPRA and to prepare them for the rigorous examinations required for attaining licensure in Canada. In order to bridge the gap in knowledge between their experience from their home country and Canadian pharmacy practice, the International Pharmacy Graduate Program or IPG program was created in the year 2000 to assist the IPGs in becoming more professionally competent, not only in therapeutic and practice knowledge, but also in communication skills. IPGs are a diverse 
group of students who come from many different countries. The top five source countries for students entering the program are Egypt, Philippines, India, Iran and Pakistan.

Several studies by Austin \& Rocchi-Dean (2004a, 2004b, 2006) describe the creation of the IPG program; however, a detailed discussion of this is beyond the scope of this paper. A key aspect of its design is that the curriculum of the IPG program was benchmarked according to the undergraduate $(\mathrm{BScPhm})$ pharmacy curriculum at the University of Toronto to ensure a high-quality education for the IPGs, and to maintain credibility with the pharmacy community and the public. The IPG program did not want to be seen by the pharmacy community and the IPGs themselves as being of poor quality or a merely a 'prep-course' for licensing exams such as the Objective Structured Clinical Examination or OSCE which was introduced as a licensing exam by the Pharmacy Examining Board of Canada (PEBC) in 2001 (Austin \& Rocchi-Dean, 2004a). Thus the P.C. Skills course does not teach students 'tips' on how to pass the OSCE, but rather how to become more competent communicators and apply their therapeutic knowledge in a Canadian health care context. Knowledge is tested primarily with patient/pharmacist simulations or role-plays which mirror how students will apply their clinical skills in pharmacy practice, and since this format is similar to the OSCE exam the course also indirectly prepares them for their licensing exam.

The development of the IPG bridging program curriculum has been researched by Austin and Rocchi-Dean (2006) who have described a "best-practice" model for bridging programs that consist of prior learning assessment (PLA) and recognition, individualized learning plans, mentorship, distance learning opportunities, and peer-network formation. In their earlier research, Austin and Rocchi-Dean (2004a) describe the instructional design of the IPG courses; specifically for the P.C. Skills course, where English language supports are built into the IPG curriculum to assist the second language learner, especially in the patient counselling interviews. This paper continues to explore this avenue of research in that it builds on the foundation of the P.C. Skills course that was originally developed by Marie Rocchi and other IPG staff. In the next section, the course construction will be discussed in relation to the broader context of communicative competency in Canadian pharmacy practice.

\subsection{Communicative Competency in Pharmacy Practice}

According to Austin and Galli (2003), communicative competency is essential for providing safe and effective patient care, and this is particularly important for pharmacists as they rely almost exclusively on interpersonal communication to make clinical decisions. Austin and Galli (2003) define it as, "the ability to convey and receive meaningful information in an accurate and consistent manner" (p. 225). Hajer and Kaskens (2012) define it as, "the ability to understand and communicate ... effectively and appropriately in a given community" ( $\mathrm{p}$. vi). Thus, communicative competency can be defined for the purposes of this paper as the ability for pharmacists to communicate effectively in a manner that meets the standards of the profession in that they are accurate and consistent in the way that they express and receive information during interactions with patients, peers and other health care professionals. Communicative competency is required in a patient-centered practice which focuses on the pharmacist's role in helping patients achieve their desired health outcomes. It is essential that 
pharmacists use effective communication skills to establish a trusting relationship with patients as a patient's trust allows the pharmacist to assist them in making informed decisions about their heath, to use medication properly, and to achieve their therapeutic goals (Tindall, Beardsley \& Kimberlin, 2003).

Indeed, a deficiency in communication skills could erode a patient's trust in the pharmacist as an expert (Nguyen, 2006; Parkhurst, 1994) and in addition, poor communication skills could result in error and patient harm and result in workplace frustration (Austin \& Galli, 2003). A near native language fluency is needed to engage in complex skills such as establishing a trusting relationship with a patient, patient interviewing, communicating care plans with physicians and other health care professionals (Austin \& Rocchi-Dean, 2004a). Second language learners, like many of the IPGs, may have challenges in obtaining these skills. It has been reported by Austin (2003) that licensed IPGs were experiencing difficulties in meeting professional standards of practice. Austin describes case reports of IPGs with poor communication skills, a lack of socio-communicative competencies, and a limited knowledge of the Canadian pharmacists' scope of practice and therapeutic knowledge base.

Austin and Rocchi-Dean (2004a) describe how the lack of communicative and cultural competency creates barriers for some of the IPGs as it can prevent them from attaining licensure. IPGs may not have the ability to communicate their therapeutic knowledge effectively in licensing exams such as the Objective Structured Clinical Exam (OSCE). The OSCE exam is a high stakes exam for all IPGs and Austin (2003) points out that IPGs often have difficulty passing licensing exams as their success rates are close to $35 \%$ on their first attempt while for the Canadian undergraduates it is closer to 95\%. However, after taking the IPG program, Austin and Rocchi-Dean (2004a) report that over 95\% of students who pass the IPG course go on and pass the licensing exams and for those students who do not pass the IPG program over $90 \%$ still go on to pass the exams. The authors note that students can still pass the licensing exams even if they don't pass the IPG program because the course is benchmarked to the higher years of the undergraduate program so students would be "over-prepared" (p. 148) to pass an entry-to-practice exam. Austin (2003) also mentions the format of the OSCE exam may be unfamiliar to many IPGs and it may present many sociolinguistic challenges which they find difficult to overcome without additional training. IPGs themselves consider patient interviewing skills, interpersonal skills and professional ethics as specific areas they needed the most assistance to prepare for licensure and practice as a pharmacist (Austin, 2003). Austin and Galli (2003) discuss the competency of IPGs in the four domains of reading, writing, speaking and listening and found that IPGs' strengths are in the reading and listening domains, and their greatest educational needs are more in the areas of writing and speaking; however, they point out that communication error in any of the four domains may have serious consequences in the high-stakes nature of pharmacy practice.

\section{Literature Review}

Virtually no studies have been published on communication courses that meet the specific language needs of internationally educated pharmacists who are second language learners. Parkhurst (2007) describes a communication course for pharmacy undergraduates who are 
non-native speakers of English. The student's fluency, as reported by Parkhurst, was sufficient enough for everyday activities, but insufficient for pharmacy communication. In order to address this learning need, a course was developed with a focus on improving verbal communication skills through activities that mirrored the professional activities of the pharmacist. Descriptions of these activities include patient counselling role-plays and presentation seminars where the students discussed patient cases with question and answer sessions. Graham and Beardsley (1986) describe the construction of a pharmacy communication course as a combination of content English as a Second Language (ESL) and English for Specific Purposes (ESP) taught by an Enhanced Language Training (ELT) specialist and a pharmacist with communication expertise. The students learned communication skills specific for pharmacy practice through various techniques such as videos, live demonstrations, and role-plays.

The use of role-plays or patient simulations in pharmacy graduate education is well described in the literature. Vyas, McCulloh, Dyer, Gregory and Higbee (2012) note how patient simulations assist students in identifying and managing patient safety concerns; Galal, Carr-Lopez, Seal, Scott and Lopez (2012) research how role-plays can help students develop social emotional competence; Vyas, Bhutada and Feng (2012) and Ragan, Virtue and Chi (2013) identify how role-plays assist students' readiness for advanced pharmacy practice experience. However, there is no information specifically for the IPG and how role-plays prepare them in similar ways as the undergraduates for professional practice.

There is a paucity of studies regarding communication courses for international medical graduates (IMGs). Cross and Smalldridge (2011) describe a multi-disciplinary approach to language learning where language instructors and clinicians work together to improve both written and verbal skills in a clinical context. Khurana and Huang (2015) describe a communication skills training program that focuses on accent modification as the IMGs' pronunciation and intonation can sometimes result in miscommunication with patients and colleagues. Hoekje (2007) offers a unique perspective on developing a course in professional communication for IMGs. Her approach conceptualizes medical communication as a secondary discourse system characterized by an ideology of science and technology, hierarchical relationships, specialized terminology and specific forms of communication such as chart writing that both the IMG and domestic graduates must navigate to succeed in the profession. By using the framework of a secondary discourse to construct the communication course, the IMG is seen not as a language learner; but instead, as a communicator, who applies their present knowledge of English to a specific context. This approach recognizes that many of the IMGs, like many IPGs, already have a high level of fluency in English as a second language or come from English speaking countries; they only need to learn to apply their language skills to the specific context of medical (or pharmacy) communication.

There are similarities in the way communication courses for IMGs and IPGs are constructed: language courses are developed to address the gap in the international professional's communication skills that may hinder their success or jeopardize patient safety and an ESP instructor develops and teaches the course with a physician or pharmacist who provides the necessary professional context. In most of these studies, ESP techniques are combined with 
profession-specific simulations such as role-plays to assist the learner in gaining language skills in the appropriate professional context. However, there may be differences between the various classroom simulations that are profession specific. For example, pharmacy simulations would focus on the pharmacist's day-to-day activities such as educating the patient on the use of their medications while the physicians may learn how to communicate with patients during a physical exam. Although these studies provide a unique ESP perspective on professional communication training for the second language learner, they do not describe a theoretical underpinning for the construction of the course. This paper will add to this literature as it describes a unique approach to pedagogy for teaching professional communication to international health care professionals.

The educational theories of Lev Vygotsky (1987) and Donald Schön (1983, 1987) will elucidate the discussion of the design of the course with Vygotskian sociocultural theory highlighting our discussion of several aspects of the curriculum which were designed to scaffold the learners and support their internalization of key aspects of the patient/pharmacist interview. Donald Schön's pedagogy of professional practice facilitates a discussion of the necessity to reduce the scaffolding and increase the IPGs' tolerance for ambiguity in the case simulations.

Other research that discusses theoretical underpinnings of bridging program construction is provided by Lum, Bradley and Rasheed (2011), who describe bridging program course construction based on Kolb's learning styles (assimilative, accommodative, convergent, divergent), and posit that this approach may help instructional designers balance their need for uniform learning outcomes that meet professional standards in a multicultural classroom with students who have diverse learning styles.

IPGs have scientific knowledge but they may have difficulty applying it to the Canadian health care context, and their lack of communicative competency makes this even more of a challenge when trying to meet professional standards (Austin, 2003). Obtaining these skills can be difficult outside of bridging programs as there is a lack of resources specifically for the second language learner as communication text books specific for pharmacy are designed for native speaker of English (Berger, 2005; Rantucci, 1990; Tindal et al,. 2003). Courses like the P.C. Skills course are essential for the IPGs, as communicative competency is crucial for their success in the licensing exams but also in professional practice. However, resources that meet the specific needs of this group are generally unavailable. There is informative research about the IPG program and its instructional design (Austin \& Rocchi-Dean 2004a, 2004b, and 2006), however, there is a gap of recent research in this area and this paper will provide a new perspective that will address this need. Before this discussion of the educational theories, a brief overview of the PC skills course will be provided in the next section.

\section{Patient Care (P.C.) Skills Course Design}

The IPG program is divided into two nine-week modules: Canadian Pharmacy Skills I or CPS I and Canadian Pharmacy Skills II or CPS II. The CPS I PC Skills course provides a foundation of communication skills and is comprised of three linked modules: Communication Skills in Pharmacy Practice, The Language of Patient Counselling (LPC) and 
the role-plays or patient/pharmacist simulations. This paper will highlight the theoretical construction of the LPC module and the role-plays as the first author helped design these courses, and has taught them for 13 years to approximately 500 students. The second author was a language instructor involved in the role plays for several years. As the Communication Skills in Pharmacy Practice is taught separately by another instructor, this paper limits its focus on these two closely connected modules. These three linked modules that run simultaneously in CPS I are illustrated Table 1.

Table 1. An overview of the PC Skills Course

\begin{tabular}{|c|c|c|c|}
\hline & \multicolumn{3}{|c|}{ Components of the PC Skills Course } \\
\hline $\begin{array}{l}\text { Aspects of } \\
\text { module }\end{array}$ & $\begin{array}{l}\text { Communication Skills } \\
\text { for Pharmacy Practice }\end{array}$ & $\begin{array}{l}\text { Language of } \\
\text { Patient Counselling } \\
\text { (LPC) }\end{array}$ & $\begin{array}{l}\text { Pharmacist Patient } \\
\text { Simulations (Role-Plays) }\end{array}$ \\
\hline $\begin{array}{l}\text { Focus of Course } \\
\text { Components }\end{array}$ & $\begin{array}{l}\text { Interpersonal and } \\
\text { Professional } \\
\text { Communication }\end{array}$ & $\begin{array}{l}\text { Patient Counselling } \\
\text { Framework }\end{array}$ & $\begin{array}{l}\text { Pharmacist Patient } \\
\text { Simulations }\end{array}$ \\
\hline $\begin{array}{l}\text { Number of } \\
\text { Instructional } \\
\text { Sessions }\end{array}$ & 12 & 7 & 8 role-plays \\
\hline $\begin{array}{l}\text { Duration of Each } \\
\text { Session }\end{array}$ & 3 hours & 3 hours & 10 minute role-plays \\
\hline Lecturer & Pharmacist & $\begin{array}{l}\text { ESL instructor and } \\
\text { pharmacist teaching } \\
\text { assistants }\end{array}$ & $\begin{array}{l}\text { Course coordinators, } \\
\text { pharmacist teaching } \\
\text { assistants and ESL } \\
\text { instructors }\end{array}$ \\
\hline
\end{tabular}

The first of these modules is Communication Skills in Pharmacy Practice, which teaches interpersonal and professional communication. A more detailed discussion of this particular module is beyond the scope of this paper, but a brief overview will be provided. The content is taught using various methods such as didactic lectures, group discussions, and role-plays that focus on topics such as assertiveness skills, empathy, communication barriers, and non-verbal communication. For example, in the lecture on non-verbal communication, students may reflect on cultural differences when communicating with non-verbal language and how it might affect the outcome of a patient interaction (e.g., students' comfort making eye contact and patient expectations in a Canadian context).

The second module, the Language of Patient Counselling, or LPC module, focuses on practical language skills and building a patient counselling framework, which can be defined as the basic underlying structure and organization of the pharmacist-patient interview. The patient counselling framework includes the following steps: introduction and greeting, information gathering (i.e., patient history), information providing (i.e., medication 
instructions), non-drug options to treat a medical condition, and a follow up or monitoring plan. Other LPC lectures focus on syntax and vocabulary, patient-centred language, proper use of modals for the following: giving instructions, discussing efficacy of the medication and putting side effects into context.

After each lecture, the language instructor and the pharmacist provide the students with a demonstration of the skills required in the role-play, and the students are given opportunities to practice with fellow learners, in small groups of three. During these in-class role-play activities, learners receive immediate feedback from their peers, from the language instructor, and the pharmacist teaching assistants. These in-class practice sessions prepare students for the third module, the patient/pharmacist simulations, where the students apply their therapeutic knowledge as well as their language and communication skills in 10 minute role-plays with an ESL instructor playing a patient, who provides feedback after the role-play on the student's communication skills while the pharmacist-TA assesses the application of the therapeutic knowledge. In the second half of the PC Skills course, in CPS II, students apply the basics skills learned in CPS I to more complex role-plays that feature communication challenges such as interviewing standardized patients who are trained to realistically portray actual patients that the IPG would meet in the community. In the next section, the educational theories used to inform the design of the P.C. Skills course in CPS I and II will be discussed.

\section{Theoretical Perspective}

\subsection{CPS I Module: Scaffolding Supports Internalization}

In CPS I, the design of the module reflects principles of Vygotskian sociocultural theory. An important concept inspired by Vygotsky's theories is that of scaffolding: "a kind of process that enables a...novice to solve a problem, carry out a task, or achieve a goal [with assistance] which would be beyond his unassisted efforts" (Wood, Bruner, \& Ross, 1976 as cited in Swain, Kinnear, \& Steinman, 2011). The main task that the students aim towards is successfully participating in their role-plays, where all knowledge is integrated in real time. In order to support their success in the role-play, several aspects of the course design scaffold their performance.

The first of these is breaking down the interview into small chunks of more manageable information. The LPC course teaches the patient interview over seven weeks and each week focuses on a particular section of the interview and this gradual building of the interview on a weekly basis supports the students in their learning without overwhelming them. Early iterations of the course provided less structure and students were struggling with the interview when it came time for them to role-play it. The instructors adjusted the amount of structure by providing more explicit instruction on each smaller segment of the interview. An example of this explicit instruction directed at each section of the interview is provided in the following section.

\subsection{Breaking Down the Interview into Sections}

There are several steps in the ideal patient interview: introduction, gathering medical information, providing information on a new prescription, identifying and managing a simple 
drug therapy problem or DTP, and completing the interview with a follow-up or monitoring plan. In the LPC module, each section of the interview is taught over seven weeks to allow students time to competently learn the various nuances of the interview without causing learner frustration. A breakdown of the LPC course content taught in each week of the course is provided in Table 2 .

Table 2. Components of the P.C. skills Course, LPC module

\begin{tabular}{|c|c|c|}
\hline Week & Class Summary & $\begin{array}{l}\text { Curriculum Details } \\
\text { (Counselling and Language Skills) }\end{array}$ \\
\hline One & $\begin{array}{l}\text { Introduction to the } \\
\text { patient counselling } \\
\text { interview }\end{array}$ & $\begin{array}{l}\text {-Greeting the patient (colloquial language) } \\
\text {-Building rapport (small talk strategies) }\end{array}$ \\
\hline Two & $\begin{array}{l}\text { Opening the } \\
\text { interview }\end{array}$ & $\begin{array}{l}\text {-Introducing yourself } \\
\text {-Confirming identity of patient/agent } \\
\text {-Informing patient/agent about information gathering } \\
\text {-Providing privacy and confidentiality } \\
\text {-Using appropriate question types and verb forms }\end{array}$ \\
\hline Three & $\begin{array}{l}\text { Proper use of the } \\
\text { documentation form }\end{array}$ & $\begin{array}{l}\text {-Learning and incorporating patient-centered language } \\
\text {-Using standard probing questions appropriately }\end{array}$ \\
\hline Four & $\begin{array}{l}\text { Information } \\
\text { providing part one }\end{array}$ & $\begin{array}{l}\text {-Names of medication (generic and brand) } \\
\text {-Indication and benefits of medication } \\
\text {-Step-by-step instructions on how to use medication } \\
\text {-Discourse markers such as "first, second...then, etc." }\end{array}$ \\
\hline Five & $\begin{array}{l}\text { Information } \\
\text { providing part two }\end{array}$ & $\begin{array}{l}\text {-Giving step-by-step instructions using precise language } \\
\text { when counselling on devices } \\
\text {-Side effects and management } \\
\text {-Storage of medication } \\
\text {-Non-drug options to manage a medical condition } \\
\text {-Language used to communicate DTPs (provide accurate } \\
\text { information without alarming patient/agent) }\end{array}$ \\
\hline Six & $\begin{array}{l}\text { Information } \\
\text { providing part three }\end{array}$ & $\begin{array}{l}\text {-Confirm patient's understanding of pharmacist's instructions } \\
\text {-The monitoring plan and follow-up phone call } \\
\text {-Concluding the information in a professional manner } \\
\text {-Understanding phrasal verbs and idiomatic expressions in } \\
\text { the Canadian health care context }\end{array}$ \\
\hline Seven & $\begin{array}{l}\text { A review of the } \\
\text { previous six weeks }\end{array}$ & $\begin{array}{l}\text {-In- class exercise where the students write out with a partner } \\
\text { a complete interview with all the above sections and then } \\
\text { role-play their interview in front of the class. Students receive } \\
\text { feedback on both the technical and communicative aspects of } \\
\text { the interview. }\end{array}$ \\
\hline
\end{tabular}


In the first lecture, greetings appropriate to Canadian pharmacy practice are discussed, which are important as they set the tone for the interview. Internationally trained professionals are sometimes overly formal in the way they greet or address patients and there is an in-class discussion on the differences between "Mrs.", "Miss" and "Ms.", as these titles are sometimes confusing to non-native speakers of English. The next two lectures focus on gathering information from the patient. Gathering medical information from the patient including allergies, medical conditions and medications is essential for patient care as the pharmacist must ensure that any new medication the patient receives is appropriate and there are no significant drug or disease interactions (NAPRA, 2009). As this is a standard of practice, it is essential that the pharmacist is thorough enough to ensure all information is gathered to prevent missing important interactions.

Creating a patient profile is often confusing for the IPG at first as this may be a new standard for them as pharmacy practice varies from country to country (Austin, 2007). In order to gather information for the patient profile, specific questions must be asked in a grammatically correct manner. For example, when pharmacists gather information for a medical history they may ask if the patient has any allergies to medication. Students may use the wrong verb tense and ask the patient, "Did you have any allergies to medications?" instead of "Do you have any allergies to medications?" When asking about medical conditions, students may ask, "How long have you been having high blood pressure?" instead of "How long have you had high blood pressure?" Educating patients on their medications is an important standard of practice (NAPRA, 2009) so it is imperative that students are taught how to provide information in a manner that is informative and accurate and ensures adherence to their medication regimen. In the information providing lectures key concepts include: patient centred language, proper use of modals for the following: giving instructions, discussing efficacy of the medication and putting side effects into context. When counselling in the role-plays students may unduly alarm patients by not putting side-effects into context and discuss uncommon side-effects without prefacing them as "rare." Also, incorrect modals are used when discussing efficacy of a drug. Students often use the modal will to discuss efficacy which incorrectly implies that the medication is going to be $100 \%$ effective. The student may incorrectly say, "If taken as prescribed, the medication will be effective to treat your medical condition." This is an unrealistic guarantee about the medication's effectiveness. The students are taught a more accurate way to describe the efficacy of a medication which is the following, "If taken as prescribed, this medication should be effective to treat your medical condition."

Another important standard of practice is identifying and managing potential drug therapy problems or DTPs. Communicating problems to patients regarding their prescription can be a delicate issue for the pharmacist as they need to inform patients of potential problems, but they don't want to blame his or her physician for prescribing an incorrect dose or an interacting drug.

In addition to learning the expectations above, students are also expected to maintain rapport with the patient during all phases of the interview. It is important for the IPG students to be competent communicators in the pharmacist/patient interview as each phase is considered an essential standard of practice, thus it can be quite a complex task for the second language learner who is uninitiated to Canadian pharmacy practice. 


\subsection{Additional Course Supports}

Other course supports include role-play demonstrations with the LPC instructor and a pharmacist TA. These exemplar role-plays provide the students with an example of what would be considered a "meets expectation" (ME) rating and an "exceeds expectation" (EE) rating. The various criteria that characterize each of these grades are discussed with the class following the demonstration. After the demonstrations, the students are provided with a complete transcription of the role-play so they can refer to it when they practice for the role-plays and pay special attention to any linguistic structures or phrases they are in the process of acquiring.

Another way student learning is scaffolded is by limiting the number of medications that can be covered in the role-plays each week. To provide more focus, the students are provided with the list of medications they are going to counsel on each week in the role-plays. This prior knowledge helps the students prepare for the role-plays. They can organize the key counselling points into a template which consolidates all the information they will provide to the 'patient' about their medication into one single chart that they can refer to during the role-play for easy retrieval. This approach is much more efficient than trying to locate information from multiple references such as the Compendium of Pharmaceuticals and Specialties (CPS) or drug product monographs during the role-play which may be nerve-wracking and waste valuable minutes during a timed role-play.

Instructors are proactive in their course design and supplementary tutorials are created on an ongoing basis to support the students in learning new concepts or procedures when it is observed that further scaffolding is required. A tutorial called Applying the Therapeutic Thought Process to the Role- Plays, commonly known as the "DTP lecture," was created for the students as the course instructors observed that students were struggling without a more explicit structure to help them manage the skill of identifying, managing and communicating drug therapy problems (e.g., the new medication cannot be taken with a current medication) during the role-plays. One potential challenge with communicating a drug therapy problem is the difficulty of expressing the problem without unduly alarming the patient. The DTP lecture added detailed linguistic and cultural content to explicitly instruct the students on this delicate linguistic balance.

Learning supports are also provided through the practice role-plays. Students have eight role-plays and three of these are practice role-plays and five of them count towards the final mark. Understandably, students are nervous about performing in front of their peers for the first time and two practice role-plays are provided at the beginning of the term to allow students an opportunity to try out their newly acquired skills and get feedback before a marked role-play. The third practice role-play is a role-play that incorporates a DTP. As this is the first DTP that the students encounter, they are given an opportunity to 'try-out' this new skill and get feedback before they move onto the next two DTP role-plays that count towards their final grade.

These various approaches to scaffolding the learning allow the students to gradually internalize the pharmacy interview structure. According to Vygotsky, "internalization is a process involved in the transformation of social phenomena into psychological phenomena" (as cited in Wertsch, 1985, p. 63) Thus, the external tools and scaffolding that are provided by 
the course design, such as the templates, transcripts, and the interactive learning of the role-plays are in the process of becoming part of their internal mental landscape over the nine weeks, becoming internalized for more confident, independent application. As a result, by the end of the first nine weeks, the majority of students are able to provide an interview that is well structured, within a 10 minute limit, with appropriate verbal and non-verbal skills. They can gather information accurately, counsel a patient on their medication including appropriate non-drug options to manage their medical condition, identify and solve and communicate a DTP and end the interview with a therapeutic monitoring plan. The next section discusses how the P.C. Skills course and its instructional design can assist IPGs in developing their communicative competency in increasingly independent ways.

After nine weeks, the students start the more advanced module: CPS II P.C. Skills. In this module, the course scaffolds as described above are dismantled to provide the student with simulations that are more ambiguous and thus, more similar to actual practice in Canada. The students have had nine weeks to internalize an interview structure and although this structure is important to incorporate all possible aspects of a 'perfect interview' students have to be prepared for the unexpected realities of professional practice. The CPS II role-plays reflect the fact that not every patient encounter is going to be laid out in a perfectly logical structure. For example, not all patients are as one-dimensional and as agreeable as the ESL instructors who portray them in the initial role-plays. In addition, in the OSCE exam and in professional practice, the medications the pharmacist dispenses are not going to be known before the patient hand him or her the prescription. Finally, in reality pharmacists are often under a lot of pressure and have to manage problems quickly and accurately with the primary goal of patient safety. A summary of the differences between CPS I and II role-plays are provided in Table 3.

Table 3. Differences between the CPS I and CPS II Role-Plays

\begin{tabular}{|l|l|}
\hline \multicolumn{1}{|c|}{ Informed by Vygotsky } & \multicolumn{1}{c|}{\begin{tabular}{c}
\multicolumn{1}{c|}{ CPS II } \\
Informed by Schön
\end{tabular}} \\
\hline Knowledge of the drugs prior to the role-play & No knowledge of the drugs prior to the role-play \\
\hline Role-plays with a simple DTP & Role-plays with complex DTPs \\
\hline Eight 10 minute role-plays & $\begin{array}{l}\text { Two 10 minute role-plays and seven 7 minute } \\
\text { role-plays }\end{array}$ \\
\hline $\begin{array}{l}\text { A linear structure with tasks known ahead of } \\
\text { time }\end{array}$ & $\begin{array}{l}\text { Variations on the role-play structure with tasks } \\
\text { not known ahead of time }\end{array}$ \\
\hline $\begin{array}{l}\text { ESL instructors as 'patients' } \\
\text { References provided are familiar to the } \\
\text { students and include: Compendium of } \\
\text { Pharmaceuticals and Specialities (CPS). }\end{array}$ & $\begin{array}{l}\text { Mix of ESL instructor 'patients' and } \\
\text { standardized patients (SPs) }\end{array}$ \\
\hline $\begin{array}{l}\text { Templates can be used as a guide when } \\
\text { counselling }\end{array}$ & $\begin{array}{l}\text { A variety of unfamiliar drug references from } \\
\text { Micromedex, Motherisk plus the CPS. }\end{array}$ \\
\hline $\begin{array}{l}\text { Seven instructional sessions describing each } \\
\text { section of the interview }\end{array}$ & $\begin{array}{l}\text { One instruction session outlining two new } \\
\text { concepts: gathering information from an existing } \\
\text { profile and documenting a patient care plan }\end{array}$ \\
\hline
\end{tabular}


5.4 CPS II module: The Ambiguity of the "Swamp Lands"

The theories of Schön provide a useful lens through which to view the increasing difficulty in CPS II and its relationship to CPS I. Schön was an educational theorist who claimed there is crisis in the professions because professionals lack the ability to solve problems that are indeterminate or "not in the book." They are only able to solve problems that are straightforward using technical expertise or what he refers to as technical rationality. He explains this phenomenon in his now famous metaphor:

In the varied topography of professional practice, there is a high, hard ground overlooking a swamp. On the high ground, manageable problems lend themselves to solution through the application of research-based theory and technique. In the swampy lowland, messy, confusing problems defy technical solution.

(Schön, 1987, p.3).

Thus, Schön argues that professionals are able to solve well-formed instrumental problems by applying theories derived from scientific knowledge on the higher ground, but he argues that this approach is limited because most problems which professionals face are not problems at all but "messy, indeterminate situations" (Schön, 1987, p.4). In order to properly prepare the IPGs for licensure and practice in Ontario, CPS II is intended to take them into the "swampy lowlands," where they are required to solve "messy situations" in a context more similar to real life practice.

This indeterminate environment in the role plays is created in the following manner: students are not given the names of the drugs prior to the role-play, students are presented with more complex cases, the role-play time is reduced from 10 minutes to seven minutes, the tasks in the role-plays are not delivered in a linear order, and standardized patients are used in three of the role-plays. For example, in CPS I, the 'patients' are played by ESL instructors, and after 12 weeks of role-plays these encounters might be too familiar or routine, as the students get to know these instructors over time. In addition, the ESL instructors rely on a script in the role- plays, which can detract from the realism of the encounter for the student. Standardized patients do not use a script in the role-play, and their professional training allows them to portray patients more realistically which can provide an element of "surprise" in the interview and challenge the students further.

\subsection{CPS II module: Examples of Ambiguous Encounters: "Therapeutic Grey Areas"}

The role the pharmacy content plays in the "messiness" of the second module can best be explained through example. In the first CPS II role-play, the students encounter a case where the management of the DTP is more complex than those they experienced in CPS I. In this scenario, the 'patient' (an ESL instructor) presents the student with a prescription for a drug called fenofibrate, which is used to treat high cholesterol. While gathering the patient's medical history using the patient counselling framework, the student learns that the patient's cholesterol is not well controlled despite the fact that he is taking another medication, atorvastatin, and this new medication is to be added to his current therapy. In the drug reference (Micromedex) provided at the station, the student reads that this new drug may 
interact with other cholesterol medications such as atorvastatin and as a result the patient may experience increased side-effects, such as muscle pain. This scenario creates an ambiguous situation for the student because the management of the interaction is unfamiliar. In previous CPS I role-plays, drug interactions were always managed simply by stopping an unnecessary drug or by directing the patient to space out the times at which the two drugs are taken. But in this scenario, the 'rules' for managing drug interactions are not as formulaic, because the reference states the two drugs may be given together to lower cholesterol, if the perceived benefits of drug therapy outweighs the risks of the interaction, and the interaction could be managed by monitoring for muscle pain while on concurrent therapy. While the reference provides the technical information to solve the case, it is limited because it is too general and not patient specific. In order to be successful in this more ambiguous role play, the students need to reflect on the situation in its entirety and include patient factors when they weigh the options, not just the technical aspects of the case.

As Austin and Galli (2003) describe, competency in the domains of reading, writing, speaking and listening are essential for clinical decision making and in this scenario, listening is an important, but often underutilized, skill. The students need to listen to the patient's dialogue to get an overall understanding of the entire case, but most students tend to gloss over this information and try to solve the case by only using the reference. In this scenario, the patient comments on his frustration of not being able to control his cholesterol levels as other medications are not effective or cause too many side effects, and this drug may be his last option. Students then are required to reflect on all parts of this scenario including the patient's concerns, the information in the reference, the other medications that were tried but were ineffective or caused too many side effects, in order to determine the right course of action for this specific case. Based on the information in the case, the student should determine that the combination of the two drugs is warranted and the side effects of the interaction is statistically significant, but rare, and the patient should be able to use both medications to control their cholesterol, but to monitor for side effects such as increased muscle pain. As Nguyen (2006) discusses, expertise is more than just verbalizing professional knowledge and in this encounter, the student needs to reflect in the moment on how to communicate technical information from the reference in a way that puts the risk and benefits of the interaction into a perspective that will inform the patient without alarming them.

The rates of success on this first role-play tend to be low and students find this new level of ambiguity to be frustrating. Some students complain that the role-play is too hard and it is unfair to grade them on something that they've never been exposed to before. However, the combination of the two drugs was discussed previously in their therapeutics course, so the students have some prior knowledge about the nature of this particular interaction. However, it may make them uncomfortable to apply it in a role-play context which is therapeutically ambiguous, potentially harmful to the patient and where their understanding of the case relies more heavily on the patient's account of their drug history. The students are initially struggling in their introduction to the swamplands, as the management of the drug interaction is not as clear-cut as it was in previous CPS I role-plays. 
5.5 CPS II module: Examples of Ambiguous Encounters: "the Uncooperative Patient"

Real world patient communication can be complex and this complexity is introduced into the CPS II role-plays with the use of standardized patients who are trained to provide the learners with a more realistic encounter. As the next example demonstrates, learners will encounter ambiguity and "surprise" in the interview when the encounter with the patient does not go as expected. In one CPS II encounter, the students meet a 65 -year -old patient named "Betty Ford." Her husband passed away and she is coming to the pharmacy to get a new prescription for an antidepressant. The students are always told to update the patient profile, but in this role-play the patient is uncooperative and tells the student that, "I just want to go home." Information gathering becomes a real "test" for the student as they are not used to this type of patient non-adherence in the role-play, and they must deviate from the typical role-play format to reflect on how to proceed with this uncooperative patient. The patient reveals she is too depressed since her husband passed away to take any of her medications, and her blood pressure is now "sky-high." According to Nguyen (2006), the student who is driven by the rules or a strict format will not be able to communicate with the patient in a meaningful way. In this role-play, it often occurs that the student is too comfortable or familiar with a rigid role-play structure, and they may fail to provide empathy to the patient and reassurance about the efficacy of her antidepressants which is the real focus of the interview. If the student is open to the learning in the role-play and less preoccupied with their agenda, the outcome of the role-play will be different. They are able to reflect in the moment that the 'patient' does not want to engage in updating of the profile or counselling, and the needs of the pharmacist may have to be "suspended" or delayed as described by Nguyen (2006) until the students change their focus to accommodate the 'patient's' needs. After this is accomplished, the 'patient' may be more focused on the pharmacist's message. The "Betty Ford" case challenges the IPG's preconceived notions of how a role-play encounter should proceed as the ELT instructors who previously played their 'patients' were always agreeable and did not withhold information. Students struggle with the complexity of this encounter and are often confused on how to proceed during the interview with their uncooperative 'patient.' However, once the interview is over, the standardized patient provides feedback on the student's communication skills and most students seem appreciative of the experience and welcome the comments. Additional student comments about the construction of the P.C. Skills course will be discussed in the following section.

\section{Course Feedback}

Course feedback has been used in the IPG program to assess the success of the program and adjust the curriculum, where appropriate, based on student feedback. For the purposes of this paper, course feedback surveys were examined for two back-to-back IPG cohorts: Fall 2010 (CPS I) and Winter 2011 (CPS II); and Spring 2011 (CPS I) and Summer 2011 (CPS II). The ethics board at the University of Toronto retroactively approved the use of these feedback surveys in this paper. The survey evaluated student satisfaction with the overall course, course assignments, readings and the course instructor using a 6-point Likert scale, and in addition the students were encouraged to answer seven open-ended questions that invited them to suggest any changes to the course, assignments and readings and to expand on what 
lectures or tutorials they liked or disliked.

In the IPG program, course evaluations are distributed in hard copy for all courses in the program at the end of CPS I and CPS II and are handed out to the students by the class representative or program staff. The office staff then transcribes the quotes onto an Excel sheet which is distributed by email to the course coordinators. The response rate for each cohort is as follows: $41 \%$ (35/85) for CPS I Fall 2010; 41\% (38/92) for CPS I Spring 2011; $70 \%$ (37/53) for CPS II Summer 2011; and 40\% (28/71) for the CPS II Winter 2011 Course. A rationale for the low response rates could be attributed to evaluation burnout as participation tends to dwindle by the fourth or fifth course evaluation. However, it is not known how many evaluations were done prior to the PC skills evaluations.

Upon reviewing the data, it was determined that the qualitative feedback provided a better understanding of student satisfaction with the course construction as the questionnaire section of the survey was not intended to capture this data. The qualitative feedback was systematically reviewed for comments relevant to Vygotsky's and Schön's theories. The following comments provide insight into the students' responses to, first, the intentional scaffolding (Vygotsky) in CPS I and two, the removal of the scaffolding to create the ambiguity of "real" practice (Schön). One student comments on how the course design had a positive outcome on their learning, "The overall structure of this course was outstanding; especially putting extra things in gradually. It was a very effective way for me to learn." Another student comments on how they appreciate this structure, "It provides a thorough analysis of the structure and function of each component of an effective interview which helps us to improve the skill to use our own knowledge in providing patient care and achieve the best [patient] outcomes." However, one student in the CPS I cohort felt that the interviewing structure was not realistic and said, "The role-play should be tailored to actual practice. I have never been counselled by a pharmacist in Canada to the extent of the role-plays. It is unrealistic." This objection could represent the tension between the necessity of the course to make explicit, and offer practice on a more extensive patient counselling framework than is used in simpler day-to-day cases. However, the authors argue that it is precisely the internalization of this framework (CPS I) and experience with ambiguous cases (CPS II) that will allow the student to make judgments about how much of the framework to apply in his or her future practice.

Students commented positively on course supports such as the role-play demonstrations with the LPC instructor and the pharmacist TA. One student comments on what s/he liked about the course, "The lectures that included the example role-plays between [the course instructors] especially when we got the script [as it] helped give a clear idea of what was expected and how to deal with similar situations." Students appreciated the transcription of the exemplar role-play and wanted the scaffolding to continue in CPS II with the standardized patients or SPs. These role-plays are less structured than the more familiar role-plays with the ESL instructors and some students clearly struggled with this new level of ambiguity. In CPS II, prior to the new standardized patient role-plays, students have a tutorial with the standardized patient trainer and the course coordinator who demonstrate a typical SP encounter. The demonstration, however, is more freeform and improvisational than the previous role-play 
demonstrations in CPS I and no transcripts are provided. One student comments about this lack of scaffolding and says they would like, "[A] transcription of the role-play for the standardized patient role-plays as a model to follow and to have an idea of the role-play." Despite having this tutorial for the standardized patient role-plays, a student comments on his frustration and comments on how he would change the course, "A tutorial on SP role-plays with situations similar to what we encounter in the role-plays so we can learn more on how to manage it, to explain more clearly what is expected from the students in the SP role-plays." Students gave feedback on other course supports in CPS I such as the in-class practice time and the counselling template. One student comments, "I am more confident now counselling patients because there is a good practice in class," and "The template is very useful. It is really organized and helped me understand the medication that I need to discuss better." Students also appreciated scaffolding like the DTP tutorial in CPS I. Student comments include, "[The] DTP is class very clear and useful," and "applying the therapeutic thought process to the role-play because that is the core of therapy we need to do when we meet the patient."

After 18 weeks of the course, students commented on how the role-plays gave them confidence when interacting with patients. According to one student, "[The course] was great for practicing skills with patients, great as a confidence boost to assist patients with questions." Students commented on other ways their interviewing skills improved during the course. One student commented on how the CPS II role-plays, "Streamlined my counselling and improved the ability to counsel more effectively." This statement could reflect how the student's interviewing skills improved because of the manner in which the CPS II role-plays are designed. As the student moves from the structured CPS I role-plays with the names of the drugs known ahead of time, the familiarity of the ESL instructor and the ten minute time limit to the more ambiguous role-plays of CPS II where students have no prior knowledge of the case and their 'patient,' the students need to streamline their role-play to complete all their tasks in only seven minutes. They have to decide in the moment what is important in the case, which means streamlining the interview to meet the needs of the patient instead of adhering to a strict role-play structure. Student feedback on the standardized patient role-plays was overall positive and some students felt there should be more of these types of role-plays. A few students commented they specifically wanted role-plays to "Include any ethical or management issues which are really important in real practice." Another student added, "It would be good if diversity is included i.e. someone with AIDS, COPD or other long term care need." It appears some students desire cases that reflect real life practice and the use of standardized patients could assist in delivering the ambiguity and complexity of these more challenging scenarios. However, role-plays with standardized patients are not always easy and one student commented that the "Standardized patient interviewing is really tricky and needs presence of mind." One student commented on how their interviewing skills progressed from the CPS I role-plays and their appreciation for the more complex cases in CPS II, "Learning interviewing skills continuing from CPS I [is] an advancement in the skills, more professional, higher level." Another student commented on how the CPS II role-plays prepared them for the shift to real life practice, "The course is a transition to the actual practice. Unreplaceable experience." 


\section{Discussion and Conclusion}

Communicative competency is a crucial skill for all health care professionals, but especially for pharmacists, because they depend primarily on effective communication to develop trusting relationships with their patients to optimize their health outcomes. Communicative competency is essential for performing the standards of practice such as patient interviewing, determining the appropriateness of drug therapy and educating patients on their medications, and this requires a high level of fluency in all the four domains of reading, writing, listening and speaking. International Pharmacy Graduates may lack a profession-specific language and local experience to apply their therapeutic knowledge in a Canadian pharmacy setting and this often creates barriers to their professional success and may prohibit them in passing licensing hurdles like the OSCE exam. Bridging programs like the IPG program at the University of Toronto were designed to assist IPGs in obtaining the skills they need to be successful in practice and research by Austin and Rocchi-Dean (2006) provide a "best-practice" model for bridging program development.

This paper is unique in this field of literature as it describes the construction of a communication course for IPGs through the lens of two very different educational theorists: Vygotsky and Schön. Scaffolding is required in the first part of course as it supports the second language learner to internalize the various nuances of the patient interview to reduce their frustration. But the course also recognizes that after a certain point, students may "over-learn" the structure and their ability to engage in what Schön $(1983,1987)$ refers to as the "swampy lowlands" of professional practice. It is this indeterminate zone where students" communicative competency will be challenged as it would in real professional practice. IPGs must have the skills to be flexible when working with the public as they present many communication challenges. Due to the high stakes nature of pharmacy practice, IPGs need to be expert communicators to minimize patient error and harm and to prevent professional frustration. The authors posit that this course construction optimizes the short period of time IPGs are in the bridging program (18 weeks) by teaching first a foundation of skills in a step-by-step manner and then build the students' communicative competency in increasingly independent ways by exposing them to situations of greater ambiguity.

An analysis of course evaluation data for both CPS I and II indicates that students appreciate the first part of the course and its design for gradual learning of concepts but they often have greater difficulty in the more ambiguous second half of the course. This is an area of research that could be expanded upon as future course surveys could focus more on specific questions that elucidate students' views on how the course construction assisted with their learning of communication skills, as well as more details about how they perceive the necessity of removing the scaffolding in CPS II. The students may feel differently about the course construction after completing the OSCE, so it would be of interest to compare their satisfaction with the course construction prior to and after taking the exam and note any difference in their perception of the course. Other avenues of future research could include a retrospective study on how the IPGs apply course concepts to their professional practice; any gaps or deficiencies identified could be used to improve future course offerings. Pharmacists' scope of practice is expanding to encompass prescribing medications and providing injections, 
so it is crucial that the P.C. Skills course keeps up with this professional expansion, so future cohorts of IPGs are equipped to communicate in these new areas of practice. IPGs comprise approximately $40 \%$ of the pharmacy workforce in Ontario and it is essential that they have a level of communicative competence that is adequate to ensure the safety of their patients. Communication courses such as the P.C. Skills course are essential for assisting international pharmacists to build their communicative competency and confidence in pharmacy practice.

\section{Acknowledgements}

The authors would like to thank Dr. Zubin Austin, Cecelia Sumi and the anonymous reviewers who contributed to the development of this paper.

\section{References}

Austin, Z. (2003). Continuous professional development and foreign-trained health care professionals. Journal of Social and Administrative Pharmacy, 20(6), 232-241.

Austin, Z. (2007). Geographical migration, psychological adjustment, and re-formation of professional identity: The double-culture shock experience of international pharmacy graduates in Ontario (Canada). Globalisation, Societies and Education, 5(2), 239-255. http://dx.doi.org/10.1080/14767720701427145

Austin, Z., \& Galli, M. (2003). Assessing communicative competency of international pharmacy graduates in Ontario, Canada. Journal of Social and Administrative Pharmacy, 20(6), 225-231.

Austin, Z., \& Rocchi-Dean, M. (2004a). Development of a curriculum for foreign-trained pharmacists seeking licensure in Canada. Pharmacy Education, 4(3/4), 143-151. http://dx.doi.org/10.1080/15602210400010224

Austin, Z., \& Rocchi-Dean, M. (2004b). Bridging education in pharmacy: The international pharmacy graduate program in Ontario, Canada. American Journal of Pharmaceutical Education, 68(5), 1-11. http://dx.doi.org/10.5688/aj6805108

Austin, Z., \& Rocchi-Dean, M. (2006). Bridging education for foreign-trained professionals: The International Pharmacy Graduate (IPG) program in Canada. Teaching in Higher Education, 11(1), 19-32. http://dx.doi.org/10.1080/13562510500400081

Berger, B. A. (2005). Communication skills for pharmacists. Washington D.C.: American Pharmacists Association.

Cross, D., \& Smalldridge, A. (2011). Improving written and verbal communication skills for international medical graduates: A linguistic and medical approach. Medical Teacher, 33, e364-e367. http://dx.doi.org/10.3109/0142159X.2011.577469

Galal, S., Carr-Lopez, S., Seal, C., Scott, A., \& Lopez, C. (2012). Development and assessment of social and emotional competence through simulated patient consultations. American Journal of Pharmaceutical Education, 76(7), 1-7. http://dx.doi.org/10.5688/ajpe7 67132 
Graham, J., \& Beardsley, R. (1986). English for specific purposes: Content, language, and communication in a pharmacy course model. TESOL Quarterly, 20(2), 227-245. http://dx.doi.org/10.2307/3586542

Hajer, A., \& Kaskens, A. (2012). Canadian language benchmarks: English as a second language for adults. Centre for Canadian Language Benchmarks. Retrieved April 29, 2015, from: http://www.language.ca/index.cfm? Voir=sections\&Id=17355\&M=4038\&Repertoire_ $\mathrm{No}=2137991327$

Hoekje, B. (2007). Medical discourse and ESP courses for international medical graduates (IMGs). English for Specific Purposes, 26, 327-343. http://dx.doi.org/10.1016/j.esp. 2006.09.002

Khurana, P., \& Huang, E. (2015). A model for a novel communication training program focused on accent modification for international medical graduates. Journal of Education and Training, 2(1), 23-40. http://dx.doi.org/10.5296/jet.v2i1.6261

Lum, L., Bradley, P., \& Rasheed, N. (2011). Accommodating learning styles in international bridging education programs. Higher Education, Skills and Work-Based Learning, 1(2), 147-168. http://dx.doi.org/10.1108/20423891111128917

Micromedex. (2013). In Micromedex online. Retrieved April 29, 2015, from http://www.micromedexsolutions.com/micromedex2/librarian/PFDefaultActionId/evidencexp ert.ShowDrugInteractionsResults

National Association of Pharmacy Regulatory Authorities. (2009). Model standards of practice for Canadian pharmacists. Retrieved April 29, 2015, from http://napra.ca/Content_ Files/Files/Model_Standards_of_Prac_for_Cdn_Pharm_March09_Final_b.pdf

Nguyen, H. (2006). Constructing 'expertness': A novice pharmacist's development of interactional competence in patient consultations. Communication \& Medicine, 3(2), 147-160. http://dx.doi.org/10.1515/CAM.2006.017

Parkhurst, C. (1994). Assessing and improving students' verbal communication abilities in pharmacy courses. American Journal of Pharmaceutical Education, 58, 50-55.

Parkhurst, C. (2007). A communication course for a linguistically diverse student population. American Journal of Pharmaceutical Education, 71(2), 1-7. http://dx.doi.org/10.5688/ aj710236

Ragan, R., Virtue, D.W., \& Chi, S.J. (2013). An assessment program using standardized clients to determine student readiness for clinical practice. American Journal of Pharmaceutical Education, 77(1), 1-7. http://dx.doi.org/10.5688/ajpe77114

Rantucci, M. (1990). Talking with patients: A pharmacists guide to patient counselling. Kingston: Weathervane Books.

Schön, D.A. (1983). The reflective practitioner: How professionals think in action. New York: Basic Books. 
Schön, D.A. (1987). Educating the reflective practitioner. San Francisco: Jossey-Bass.

Swain, M., Kinnear, P., \& Steinman, L. (2011). Sociocultural Theory in Second Language Education: An Introduction through Narratives. Bristol, UK: Multilingual Matters.

Tindall, W., Beardsley, R., \& Kimberlin, C. (2003). Communication skills in pharmacy practice. New York, NY: Lippincott Williams and Wilkens.

Vyas, D., Bhutada, N.S., \& Feng, X. (2012). Patient simulation to demonstrate students' competency in core domain abilities prior to beginning advanced pharmacy practice experience. American Journal of Pharmaceutical Education, 76(9), 1-10. http://dx.doi.org/10. 5688/ajpe 769176

Vyas, D., McCulloh, R., Dyer, C., Gregory, G., \& Higbee D. (2012). An interprofessional course using human patient simulation to teach patient safety and teamwork skills. American Journal of Pharmaceutical Education, 76(4), 1-9. http://dx.doi.org/10.5688/ajpe76471

Vygotsky, L. (1987). The collected works of L. S. Vygotsky, Volume 1: Problems of general psychology. New York, NY: Plenum Press.

Wertsch, J. V. (1985). Vygotsky and the social formation of the mind. Cambridge, MA: Harvard University Press.

\section{Copyright Disclaimer}

Copyright reserved by the author(s).

This article is an open-access article distributed under the terms and conditions of the Creative Commons Attribution license (http://creativecommons.org/licenses/by/3.0/). 